ИЛЬИЧЕВА Людмила Ефимовна - доктор политических наук, профессор; директор программ иентра государственно-частного партнерства Института государственной службы и управления РАНХиГС при Президенте РФ (119606, Россия, г. Москва, пр-кт Вернадского, 84; lilitcheva@таil. ru); главный научный сотрудник Института социально-политических исследований ФНИСЦ РАН ЛАПИН Андрей Викторович - кандидат политических наук, доцент кафедры управления проектами и программами факультета государственного управления экономикой Института государственной службы и управления РАНХиГС при Президенте РФ (119606, Россия, г. Москва, пр-кт Вернадского, 84; av.lapin@igsu.ru)

\title{
АНАЛИЗ МОДЕЛЕЙ ЭКОСИСТЕМ В РАКУРСЕ СОЦИАЛЬНОЙ ДЕПОЛЯРИЗАЦИИ В ОБЩЕСТВЕ
}

\begin{abstract}
Аннотация. Сегодня в сознании общества закрепился технократический подход к термину «экосистема», который ассоциируется с образом совокупности технологических платформ, как правило, цифровых, предоставляющих клиенту продукты и услуги в формате одного окна. Однако природное происхождение понятия «экосистема» диктует применение другого подхода, основанного на взаимодействии внутри экосистемы субсистемы живой и неживой природы, включая людей, и неорганической среды в форме социально-экономической субсистемы, в результате которого экосистема оказывается способной предоставить обществу так называемые экосистемные услуги. Развивая гипотезу о природоподобии социальных процессов в обществе, авторы выдвигают идею, что высшей формой организации экосистемы будет модель социально-политической суперэкосистемы, в которой реализуется переход к самоорганизующейся, саморегулирующейся, саморазвивающейся экосистеме, созданной по модели политической сети. Здесь взаимозависимые экосистемы, организации и группы граждан при координирующей роли головной организации - провайдера взаимодействуют между собой для обеспечения достижения общественно значимого стратегического приоритета. В такой суперэкосистеме единое государственное целеполагание, общность морально-этических и ценностных установок экосистемных акторов, возможность достижения взаимной выгоды участников и граждан от осуществляемой общественно значимой экосистемной деятельности позволят поддерживать низкий уровень социальной напряженности в обществе и тем самым предупредить возникновение очагов групповой социальной поляризации.
\end{abstract}

Ключевые слова: природная экосистема, социальная экосистема, природоподобные системы, экосистемные услуги, социальная напряженность, деполяризация

Статья написана при финансовой поддержке РФФИ в рамках научно-исследовательского проекта № 21-011-31709 «Механизмы и технологии социально-экономической и политической деполяризации в российских регионах».

B своей речи 30 ноября 2021 г. на инвестиционном форуме «Россия зовет!» президент России В.В. Путин заявил, что для развития национальной экономики, повышения производительности труда и доходов граждан важно обеспечить сбалансированное развитие цифровых экосистем, которые должны строиться вокруг человека и его так называемого цифрового профиля ${ }^{1}$. В приведенной интерпретации под словом «экосистемы» президент России скорее

\footnotetext{
${ }^{1}$ Инвестиционный форум «Россия зовет!». Владимир Путин в режиме видеоконференции принял участие в пленарной сессии форума «Россия зовет!». - Официальный сайт Президента РФ. 30.11.2021. Доступ: http://www.kremlin.ru/events/president/news/67241 (проверено 07.01.2022).
} 
всего подразумевал специальную цифровую платформу, которая является ключевым инструментом цифровой трансформации национальной экономики, способной дать серьезный эффект для развития страны и повышения благосостояния граждан. Действительно, такой преимущественно информационнокоммуникативный подход к понятию «экосистема» закрепился в сознании политической элиты страны в первую очередь благодаря стремительному развитию инноваций, связанных с Интернетом, сетевыми технологиями, искусственным интеллектом и другими цифровыми технологиями, которые создают иллюзию повышения эффективности управленческих процессов, разработанных, как правило, еще в аналоговую эпоху. Примером продвижения столь односторонней экосистемной повестки можно назвать публикацию доклада для общественных консультаций «Экосистемы: подходы к регулированию», подготовленного Банком России, в котором экосистемы предстают в виде совокупности нескольких платформ, с помощью которых клиенту предоставляются различные продукты и услуги по принципу одного окна1

Такой технократический подход, на наш взгляд, серьезно упрощает, вульгаризирует роль экосистем, сводя ее к выполнению функции системного интерфейса, соединяющего компании-поставщики с потребителями. В реальном же обществе производители и покупатели, помимо коммуникации между собой, взаимодействуют еще и с властными структурами, бизнес-сообществами, другими организациями и гражданами, которые, следуя своим сложным и противоречивым интересам, влияют на поведение как поставщиков, так и потребителей экосистемной продукции, тем самым изменяя их суждения о рациональном образе существующих и перспективных экосистем.

В этом смысле для лучшего понимания роли экосистем в обществе целесообразно сменить технократический подход на подход с учетом возможных последствий социального взаимодействия участников экосистемы как между собой, так и с внешними по отношению к этой экосистеме силами. Для анализа социального взаимодействия примем определение, предложенное академиком Г.В. Осиповым: это «любое значимое для общества и его членов поведение индивидов, различающихся по виду деятельности, функциям и социальным статусам» [Осипов 2010]. При таком социокультурном подходе облик экосистемы нужно будет уже определять как производную от социального взаимодействия акторов, нацеленного на поддержание баланса интересов всех участников экосистемы. А т.к. экосистемное социальное взаимодействие затрагивает интересы большого числа организаций, властных и общественных структур, групп интересов граждан и т.Д., то и исследовать генезис происхождения и развития экосистем следует в парадигме изучения социально-политических процессов.

Некоторые аспекты трансформации понятия «экосистема» из природного начала в социально-экономическое толкование, разъясняющее механизм образования экосистемных услуг, были исследованы одним из авторов настоящей статьи ранее [Лапин, Цветкова 2021]. Но чтобы придать этому термину новую политологическую окраску, следовало бы уточнить ряд его смысловых граней.

На наш взгляд, начать анализ целесообразно с рассмотрения событий 20 -х гг. XX в., когда в чикагской школе социологии города (R. Park, E. Burgess, R. Mckenzie) была разработана социально-экологическая концепция эколо-

1 Экосистемы: подходы к регулированию: доклад для общественных консультаций. М.: Банк России. 2021. 45 с. Доступ: https://cbr.ru/Content/Document/File/119960/Consultation Paper_02042021.pdf (проверено 07.01.2022). 
гии человека, которая представляла общество как организм, имеющий, кроме социального (культурного) уровня, так называемый биотический уровень, лежащий в основе всего социального развития и, в конечном итоге, определяющий социальную организацию общества [Стегний 2009: 31]. Представители этой школы утверждали, что экологический порядок выступает природной почвой всех общественных отношений, а также ограничительным условием функционирования общества и условием его выживания. Согласно концепции экологии человека, эволюция от биотического до социального уровня проходит четыре фазы:

- экологический порядок, в котором результат пространственного, физического взаимодействия индивидов («социальных атомов») достигается в условиях борьбы за выживание на биотическом уровне;

- экономический порядок, в котором результат торговли и обмена между индивидами достигается в условиях конкурентного конфликта между производителями и потребителями;

- политический порядок, в котором вследствие более тесных и разнообразных связей конкуренция между индивидами приобретает форму конфликта, разрешаемого средствами политики путем контроля и урегулирования с целью установления социальной солидарности;

- культурный порядок, в котором тесное неформальное и многообразное взаимодействие индивидов осуществляется в условиях конкурентной культурной ассимиляции [Park 1955: 313].

Поскольку пространственные отношения людей, как утверждали представители чикагской школы социологии города, являются продуктом конкуренции и отбора пространственных предпочтений человеческих институтов и самого человека, то их смена в силу влияния новых факторов приводит к соответствующим изменениям на уровне физического базиса социальных отношений. Отсюда был сделан основополагающий вывод о необходимости динамичного поддержания равновесия общества и среды в ходе всего социально-исторического процесса развития общества. Однако следует отметить, что причинные связи индивидуумов как социальных организмов со средой их обитания и жизнеобеспечения не подвергались глубокому изучению.

Применение социально-экологического подхода к понятию «экосистемные услуги» дает нам возможность визуализировать схему функционирования природной экосистемы, выделив в ней природную и экономическую составляющие (субсистемы), которые в результате своего взаимодействия генерируют пользу для общества (см. рис. 1).

Представленная на рис. 1 схема определенно указывает на то, что критерием ценности для общества природной экосистемы, в конечном счете, будет уровень востребованности и качества тех экосистемных услуг, которые она в совокупности сможет предоставить обществу. Из этого можно сделать вывод, что значимость природной экосистемы, как и любой другой, определяется ее способностью приносить пользу обществу.

Таким образом, экосистемный подход к социальной организации общества, в котором человек находится в пространственной взаимосвязанности со средой, технологиями и организацией деятельности, характеризуется тем, что при исследовании общества применяется аналогия с природными экосистемами, где все элементы функционируют таким образом, что все имеет свое место и ничего не тратится впустую. Исходя из этого подхода, в случае, если в экономике получится создать нечто похожее, эффективность такой промышленной экосистемы гипотетически будет на самом высоком уровне. Следовательно, 


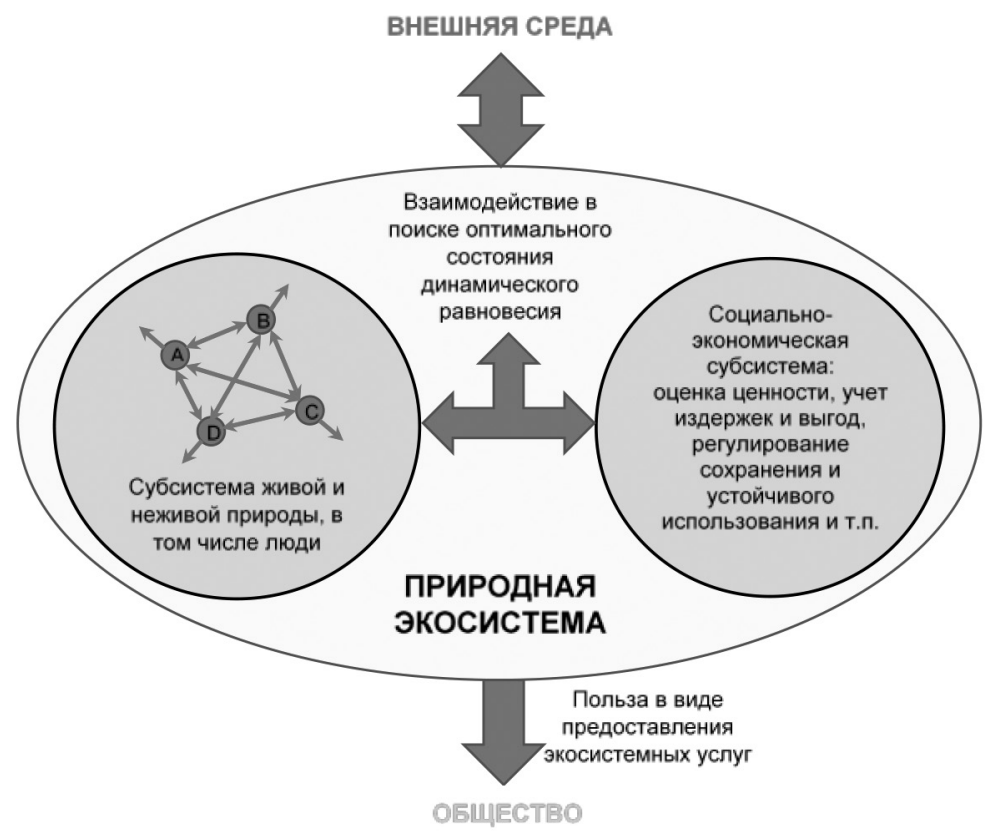

Рисунок 1. Схема функционирования природной экосистемы $(A, B, C$ и $D-$ сообщества организмов, включая людей, взаимодействующие с неорганической окружающей средой).

при проектировании устойчивых промышленных систем можно использовать принципы природоподобия, выявляемые при изучении природных систем.

Исходя из этого посыла, R. Frosch и N. Gallopoulos в 1989 г. предложили концепцию промышленной экосистемы (industrial ecosystem), в которой избыточные ресурсы, генерируемые промышленным процессом в одной компании, должны собираться и перенаправляться для использования в качестве «нового» вклада в процессы, генерируемые в других компаниях, обеспечивая тем самым взаимную выгоду или симбиоз [Frosch, Gallopoulos 1989]. Однако даже сами авторы отмечали, что идеальная экосистема, в которой использование энергии и материалов оптимизировано, отходы и загрязнение сведены к минимуму, а каждому продукту производственного процесса отводится экономически обусловленная роль, будет достигнута еще не скоро.

Тем не менее идея природоподобия промышленных систем продолжала волновать умы исследователей, и, наконец, в 1993 г. была опубликована известная работа J. Moore «Predators and Prey: A New Ecology of Competition» («Хищники и добыча: новая экология конкуренции»), в которой он предложил концепцию предпринимательских экосистем (business ecosystem), где сообщества функционируют и развиваются по законам, близким к закономерностям экологических систем [Moore 1993]. Джеймс Мур рассматривал компанию не как представителя одной отрасли, а как часть бизнес-экосистемы, которая охватывает различные, даже не смежные отрасли. В этой бизнес-экосистеме компании совместно развивают новую инновацию: они сотрудничают и одновременно конкурируют друг с другом, чтобы поддерживать новые продукты, удовлетворять потребности клиентов и, в конечном итоге, внедрять следующий цикл инновации. По мнению Дж. Мура, как раз конкуренция между бизнес-экоси- 
стемами, а не отдельными компаниями в значительной степени способствует современной промышленной трансформации, выжить в которой могут лишь наиболее приспособленные бизнес-экосистемы.

Именно вследствие жесткой конкуренции бизнес-экосистемы в своем развитии постепенно переходят от случайно сложившейся конфигурации компаний к все более структурированному сообществу, имеющему четкие организационные границы, в рамках которого бизнес-экосистемы либо проходят процесс самообновления, либо распадаются.

Исходя из принятого допущения об определенной идентичности принципов эволюции природных и экономических систем, можно визуализировать схему функционирования бизнес-экосистемы, выделив в ней субсистему компаний и социально-экономическую субсистему, которые в результате своего взаимодействия генерируют экосистемные услуги для общества в виде продуктов и/или услуг (см. рис. 2).

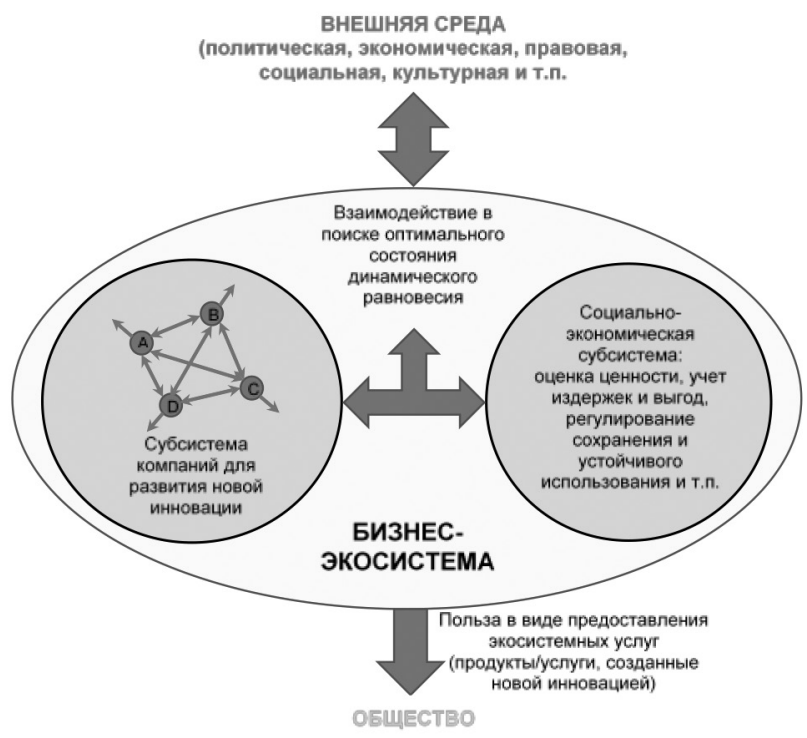

Рисунок 2. Схема функционирования бизнес-экосистемы ( $A, B, C$ и $D$ - компании, принимающие участие в разработке и продвижении новой инновации).

B 2003 г. E. Mitleton-Kelly в статье, посвященной функционированию социальной экосистемы, провела определенные параллели с бизнес-экосистемой, представив социальную экосистему как сложную эволюционирующую систему, состоящую из связанных между собой и совместно развивающихся отдельных полноправных предприятий, потребителей и поставщиков, а также экономических, культурных и правовых институтов, которые одновременно являются полноправными участниками социальной экосистемы, влияют друг на друга и находятся под ее влиянием [Mitleton-Kelly 2003]. При исследовании социальной экосистемы она исходила из гипотезы, что сосуществование и развитие организаций и институтов происходит на общих принципах для всех природных сложных систем, однако делала оговорку, что этот посыл является всего лишь отправной точкой исследования, т.к. люди обладают способностью размышлять, делать осознанный выбор среди альтернатив и принимать решения, в отличие от поведения биологических, физических или химических объектов. 
При сравнении описания бизнес-экосистемы и социальной экосистемы можно заметить, что социальная экосистема - это, по сути, следующая стадия эволюции бизнес-экосистемы, в которую, кроме самих предприятий и организаций, действующих в условиях высокой конкуренции, включены также экономические, культурные и правовые институты, не являющиеся компонентами экосистемы, но принимающие участие в создании и поддержании регуляторной субсистемы бизнес-экосистемы, обеспечивающей взаимодействие предприятий и организаций в поиске оптимального состояния их динамического равновесия.

Тем не менее применение социально-экономического подхода к анализу моделей экосистем не дает ответа на четыре вопроса.

1. Почему в подобных экосистемах (бизнес-экосистема, социальная экосистема, можно упомянуть еще социально-экономическую экосистему, инновационную экосистему, университетскую предпринимательскую экосистему и др.) [Фадейкина, Малина 2021] исследуется взаимодействие только между организациями - участниками рынка, а не между людьми как живыми организмами, представляющими эти организации в ходе проведения переговорного процесса по поиску баланса интересов участников, исходя из субъективного видения этими представителями корпоративной экономической целесообразности?

2. Что является общим значимым интересом для всех участников экосистемы, достижение которого способствует выстраиванию консенсуса между ее участниками и сплачивает их в борьбе с конкурирующими экосистемами?

3. Каким образом происходит самоорганизация и саморегулирование деятельности участников экосистемы, отбор и развитие наиболее эффективных и отторжение некомпетентных предприятий и организаций?

4. Каким образом происходит взаимодействие экосистем, деятельность которых развивается в том или ином государстве, с соответствующими органами государственной власти в рамках действующей нормативно-правовой среды?

Ответы на эти вопросы очевидным образом отсылают нас к трактовке понятия «экосистема» по примеру сетевого общества, которое, как писал М. Кастельс, «создано сетями производства, власти и опыта, которые образуют культуру виртуальности в глобальных потоках, пересекающих время и пространство» [Кастельс 2000: 505]. Действительно, экосистема состоит из множества взаимодействующих между собой отдельных объектов, являющихся ее одушевленными и неодушевленными участниками, влияющими друг на друга и находящимися под влиянием самой экосистемы. Взаимовлияние объектов в экосистеме осуществляется посредством коммуникативных процессов между индивидами, представляющими институты, с использованием каналов связи и общения в сетевом обществе. По словам О.М. Михайленка, аналогичное взаимодействие происходит «между конституирующими элементами, являющимися так называемыми энергетическими узлами или точками сосредоточения кумулятивной энергии взаимодействия индивидов или их групп» [Политические отношения... 2021: 124].

Логика построения экосистемы не предполагает непосредственного участия в ней институтов гражданского общества, поскольку смысл существования экосистемы состоит в совместном коммерческом развитии инновационного продукта для удовлетворения потребностей клиентов, а общественные институты призваны сдерживать не только государство, но и рынок, чтобы не дать обществу впасть в соблазн получения рыночной прибыли. В сетевом обществе также превалирует роль технологий, власти потоков и логики рынков, которая настолько повсеместна и всепроникающа, что, как отмечал М. Кастельс, един- 
ственный путь выхода общественных институтов из-под ее господства - это переход на другую систему ценностей и убеждений [Кастельс 2000].

Однако в силу объективно обусловленного процесса развития той или иной экосистемы, в которой играющие по правилам сетевого взаимодействия взаимозависимые акторы являются бенефициарами, действующими в целях приобретения собственных экономических выгод, совокупная доля рынка, занимаемая такими экосистемами, может достигнуть впечатляющих масштабов. Это ставит вопрос о необходимости проведения оценки меры социальной ответственности участников экосистемы перед собственными работниками и перед обществом, которая может оказаться весьма значимой. Исходя из этого посыла, можно признать, что социальная экосистема имеет характерные признаки корпоративной структуры, заключающиеся в наличии групп интересов, которые «относятся либо к социально-профессиональным, либо к институциональным их категориям» [Перегудов 2006], группировании внутри себя и вокруг себя такого большого числа людей, деятельность которых существенно влияет на состояние окружающей среды, качество потребительских товаров, трудовые отношения между работодателями и работниками и т.д. ${ }^{1}$ Поэтому экосистема, подобно корпорации, может быть включена в систему отношений, существенно определяющих состояние социальной сферы как в отдельных сегментах общества, так и во всем обществе в целом, в котором действует совокупность динамично развивающихся экосистем. Это рассуждение позволяет придать экосистемам статус социально-политического института, в котором социальные аспекты деятельности неотделимы от аспектов экономических. Более того, наделение социальной экосистемы признаками корпорации позволяет распространить на нее концепцию корпорации как компании участников (stakeholders company), согласно которой, по мнению С.П. Перегудова, корпоративными участниками являются не только ее акционеры, менеджеры и наемный персонал, но и органы местного самоуправления, и ответственные за состояние социальных услуг органы центральной власти, и прилегающие к предприятиям корпорации местные сообщества (communities), а также проявляющие интерес к их деятельности организации гражданского общества ${ }^{2}$. Это означает, что социальная экосистема не имеет четких границ и исчерпывающей конфигурации участников. В сферу ее притяжения могут попадать как организации, так и отдельные граждане, заинтересованные в получении выгоды от деятельности экосистемы, но не являющиеся при этом непосредственными ее участниками, и ограничивающиеся попытками влияния на принимаемые участниками экосистемы решения. Но что еще более важно, это то, что статус социально-политического института обязывает государство решать задачу регулирования деятельности экосистем в целях коHтроля уровня их рыночной власти и недопущения возрастания их могущества до точки политических притязаний.

Придание социальным экосистемам статуса социально-политического института позволяет рассматривать их деятельность через призму теории политических сетей, согласно которой многообразие государственных и/или негосударственных акторов взаимодействует между собой с целью продвижения общих интересов на основе баланса интересов и ресурсной взаимозависимости, признавая при этом, что их кооперация является наилучшим способом достижения общих целей [Borzel 1998: 254]. По мнению А.В. Бреги, при исследовании политических отношений взаимодействующих государственных

${ }^{1}$ Перегудов С.П. Корпорация как социальный институт. - Независимое военное обозрение. 23.03.2004. Доступ: https://nvo.ng.ru/ideas/2004-03-23/11_corporation.html (проверено 07.01.2022).

2 Там же. 
и/или негосударственных акторов следует исходить, во-первых, из их политической асимметричности, в основе которой лежит иерархичность отношений, во-вторых, из сетевого характера их отношений, предполагающего горизонтальное взаимодействие акторов [Политические отношения... 2021]. Из этого предположения А.В. Брега делает важный вывод, что для выявления факторов и способов динамического взаимодействия между властью, бизнесом и обществом необходима конвергенция традиционных и сетевых концептуальных подходов, в рамках которой предполагается присутствие в политике как иерархических, так и сетевых структур в разных соотношениях друг с другом, а также сосуществование двух типов политической сети - иерархической и горизонтальной. А это, в свою очередь, означает наличие в сетевом обществе (и в экосистеме как его разновидности) определенной иерархической структуры, в рамках которой один из акторов, обладающий бо́льшими, чем остальные акторы, ресурсами, выполняет функцию центра, что позволяет ему продвигать собственный дизайн конфигурации участников, а также свое видение общих интересов и скорости движения участников для их достижения.

Следуя этому посылу, можно представить экосистему как сеть с лидирующей организацией, которая обеспечивает управление сетью и снижает затраты всех участников сети на достижение общих целей экосистемы, беря на себя издержки управления [Сморгунов, Шерстобитов 2014]. В такой экосистеме вся сетевая деятельность и ключевые решения координируются одним из акторов экосистемы, выполняющим функцию провайдера, которого могут определять участники экосистемы или устанавливать внешние ресурсодержатели.

Исходя из этого, в социальных экосистемах, в отличие от природных (в которых взаимодействие живых организмов осуществляется в хаотичном порядке), происходит упорядочение взаимодействия акторов путем выделения командного сообщества (провайдера), выполняющего роль экосистемного управления, задающего экосистеме конкретные задачи достижения тех приоритетов, которые являются ключевыми для провайдера, например повышение прибыли, увеличение оборота финансовых средств, повышение объема пассажироперевозок и т.д. Именно провайдер определяет дизайн экосистемы, функции, число и содержание платформ, входящих в бизнес-экосистему, а также набор экосистемных услуг, предоставляемых обществу. Число самих экосистем ограничено только ресурсными, организационными и интеллектуальными возможностями провайдеров производить платформы и запускать их в эксплуатацию.

Однако следует отметить, что в социальной экосистеме, несмотря на ее социально-политический статус, политическая составляющая выражена в основном социальной функцией, связанной с социальной ответственностью участников перед обществом, и претензии на политическое влияние отсутствуют или своевременно купируются публичной властью.

Таким образом, можно визуализировать схему функционирования социальной экосистемы как следующую эволюционную стадию развития бизнес-экосистемы (см. рис. 3).

В результате проведенного анализа социальных экосистем с использованием социально-экономического, сетевого, корпоративного и других подходов можно сформулировать некоторые характерные признаки социальных экосистем в их современной интерпретации:

- экосистемы в силу занимаемой совокупной доли рынка, концентрации внутри себя и вокруг себя больших масс людей, от деятельности которых во многом зависит социально-экономическое состояние общества, должны рас- 


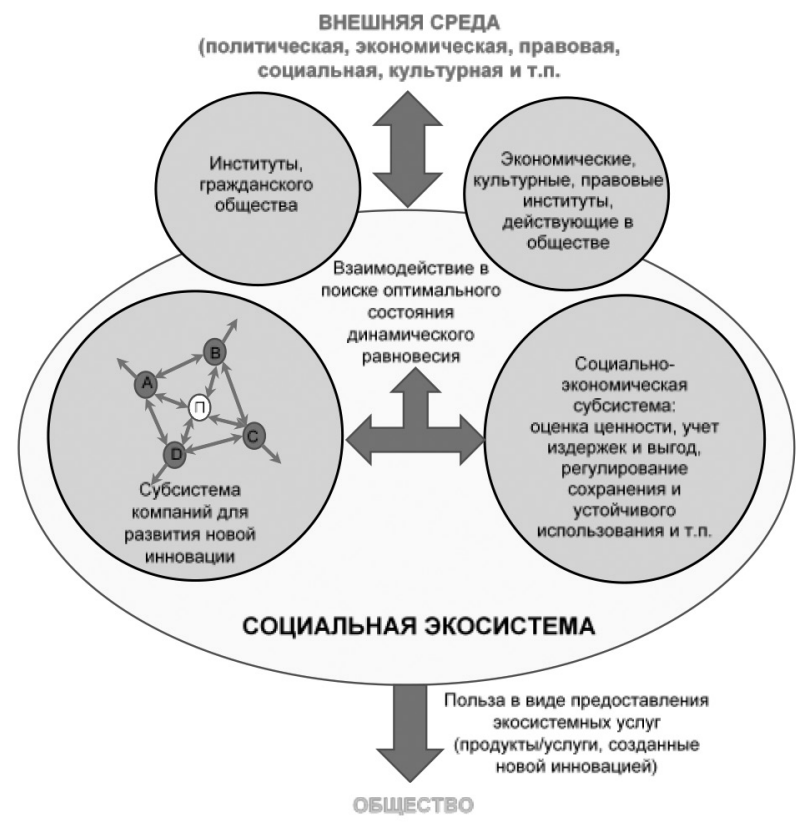

Рисунок 3. Схема функционирования социальной экосистемы $(A, B, C$ и $D$ - компании, принимающие участие в разработке и продвижении новой инновации, П - компания, выполняющая функцию провайдера социальной экосистемы).

сматриваться как социально-политические институты, вследствие чего их функционирование подлежит государственному регулированию;

- исходя из приобретаемого социально-политического статуса, экосистемы могут быть включены в систему социальных отношений с возложением на них части государственных обязательств по содержанию социальной сферы;

- в силу приобретаемого статуса социально-политического института экосистемы могут быть включены в систему создания и реализации общественно значимых продуктов и/или услуг на принципах государственно-частного партнерства;

- в экосистеме реализована сетевая организация взаимодействия участников, в рамках которой непосредственно коммуникацию осуществляют представители участников, исходя из делегированных им участниками полномочий по защите их интересов;

- сетевая сущность экосистемы определяет точку сборки участников экосистемы - общий кооперативный интерес, который определяет конфигурацию ее участников, их поведение в процессе саморегулируемого поиска баланса интересов, а также результаты их совместной деятельности по достижению общего кооперативного интереса;

- координация деятельности участников в экосистеме осуществляется лидирующим участником, обладающим наибольшими ресурсами, компетенциями и другими преимуществами, позволяющими ему выполнять функции провайдера и при этом продвигать собственное видение направлений развития экосистемы;

- институты гражданского общества, органы центральной власти и местного 
самоуправления, местные сообщества не входят в число непосредственных участников экосистемы, но взаимодействуют с ними по вопросам, представляющим взаимный интерес.

Из представленного анализа моделей экосистем можно увидеть, как постепенно совершался эволюционный переход:

- от осознания сущности природных экосистем, в которых взаимодействуют друг с другом живые организмы внутри неорганической среды и биосферы (экологический порядок в представлении ученых чикагской школы социологии города);

- через понимание экосистемы как предпринимательской сложной эволюционирующей системы, состоящей из связанных между собой и совместно развивающихся в рамках сообщества отдельных предприятий, потребителей и поставщиков, а также экономических, культурных и правовых норм и правил внутренней социально-экономической субсистемы (экономический порядок, согласно концепции чикагской школы социологии города);

- к самоорганизующейся, саморегулирующейся, саморазвивающейся социальной экосистеме, созданной по модели политической сети, в которой взаимозависимые акторы при координирующей роли лидирующей организациипровайдера взаимодействуют между собой для обеспечения баланса интересов в целях достижения общего кооперативного и/или общественно значимого интереса (социальный порядок).

Можно сказать, что экосистемный подход в определенной степени детализирует цивилизационный подход к общественному развитию, поскольку рассматривает все факторы общественного развития более глубоко и комплексно, в т.ч. с учетом интересов всех ключевых акторов - власти, бизнеса и общества. Это предполагает не только изучение экосистем с помощью анализа их внутренней структуры, исследования взаимоотношений участников, взаимообусловленности их действий и т.п., но и постижение нюансов взаимодействия как участников, так и экосистемы в целом с внешней средой, в которой конкуренция с другими экосистемами и организациями будет приобретать форму конфликта, который может быть разрешен только политическими средствами.

В этом смысле можно заметить, что социальные экосистемы уже обладают некоторыми признаками политической системы, характеризующейся, как говорил Д. Истон, наличием совокупности взаимодействий, посредством которых ценности (повышение качества жизни населения, устойчивое развитие и др.) авторитарным способом привносятся в общество [Easton 1953]. Так как сегодня ценности в общество, как правило, привносятся через механизм реализации баланса интересов власти, бизнеса и общества, это позволяет предположить, что дальнейшая эволюция социальной экосистемы будет проходить в направлении обретения ею функции управления взаимодействием акторов, действующих внутри социума, в целях достижения баланса интересов по вопросам общественного развития и безопасности.

Этот вывод заставляет нас посмотреть на экосистему иным образом - как на сегмент общества, функционирующий по модели конструкта «мы - группа» [Ильичева, Кондрашов, Лапин 2021], согласно которой в этом сегменте (а экосистема, несомненно, является таким элементом общества) может образовываться устойчивая коалиция акторов, имеющих общую систему релевантностей и схожее понимание образа жизни и, как следствие, формирующих групповой уровень своей экосистемной идентичности. Данное допущение выводит нас к пониманию того, что внутри социальной экосистемы группы индивидов в своем большинстве будут, как правило, разделять ценности, формируемые и культивируемые в сообществе экосистемных акторов. Принятые в социальной 
экосистеме ценности, основанные на схожих этических обычаях, взаимных моральных обязательствах и других нравственных установках, будут в позитивном плане влиять на уровень социальной напряженности между индивидами, действующими в рамках экосистемы. При таком подходе существенно возрастает роль провайдера социальной экосистемы, т.к. в случае возникновения в границах экосистемы какого-то социального конфликта провайдер по праву организатора экосистемного управления может принять на себя функцию медиатора или арбитра, регулирующего на своей коммуникативной площадке споры между участниками и работниками экосистемы.

Однако следует отметить, что морально-этические и ценностные установки одной социальной, предпринимательской или иной экосистемы могут существенно отличаться от установок, которые исповедуют участники других экосистем. Вследствие этого объективно существующая конкуренция между отдельными экосистемами по экономическим вопросам может усилиться за счет конфликтов, имеющих социальный и ценностный характер, что может привести к эскалации конфликтов и споров как между самими экосистемами, так и между отдельными экосистемами и обществом. В этом случае роль арбитра может взять на себя только государство, обладающее неотъемлемым правом регулировать деятельность экосистем как социально-политических институтов на основе единого для всех экосистем понимания государственного целеполагания (образа будущего государства). Поэтому неизбежным представляется грядущий процесс скорейшего инкорпорирования социальных экосистем в действующую нормативно-правовую среду, формирующую предпосылки для образования уже социально-политической экосистемы. В такой экосистеме провайдером могла бы стать организация, поддержанная государством как целеполагающим органом, способная обеспечить эффективное экосистемное управление по достижению государственного стратегического приоритета, а также социально-политическое регулирование как межэкосистемных отношений, так и взаимоотношений подведомственных экосистем с обществом. Такие отношения необходимо выстраивать на принципах доверительности, социальной толерантности и взаимной выгоды при производстве общественно значимых продуктов и/или услуг в рамках соответствующей экосистемной деятельности.

Формирование подобной социально-политической суперэкосистемы знаменует собой внедрение экосистемного подхода в публичной политике и позволит развить систему гражданского партнерства, в т.ч. через сложную цифровую инфраструктуру, с помощью которой взаимодействуют между собой политические элиты, органы государственной власти, граждане, институты гражданского общества, бизнес-структуры. Отличительной чертой социально-политической суперэкосистемы от социальной является то, что в ней взаимодействуют друг с другом не только участники сообщества компаний для развития инноваций внутри экосистемы, но и социальные, предпринимательские и иные экосистемы, организации и сообщества граждан в целях обеспечения общества продуктами/услугами по отдельному стратегическому направлению социально-экономического развития страны (например, для реализации таких проектных инициатив правительства России, как «Политика низкоуглеродного развития», «Чистая энергетика (водород и ВИЭ)», «Цифровой профиль гражданина» и др. $\left.{ }^{1}\right)$.

1 Распоряжение Правительства РФ от 06.10.2021 № 2816-р «Перечень инициатив социально-экономического развития Российской Федерации до 2030 года». Доступ: http:// static.government.ru/media/files/jwsYsyJKWGQQAaCSMGrd7q82RQ5xECo3.pdf (проверено 07.01.2022). 
Задача такого рода социально-политической суперэкосистемы - обеспечение взаимодействия и защита интересов всех участников в процессе достижения стратегических приоритетов путем выявления проблем и рисков на этом направлении, формирования политических и социально-экономических решений по преодолению выявленных угроз и вызовов, снижению социальной напряженности, возможной деполяризации общества и имплементации принятых решений. Это означает, что социальная экосистема будет эволюционировать от модели отдельной экосистемы как совокупности организаций и институтов, соединенных многомерными внутренними связями, не скованными пространственными границами и имеющими своей целью обслуживание отдельных сегментов общества, к модели экосистемы экосистем, которая включает в себя все действующие в обществе эко- и недоэкосистемы, цель которой - обслуживание всего общества по отдельному стратегическому направлению социально-экономического развития, но уже на принципиально другом по сравнению с социальными экосистемами уровне управления.

Данное рассуждение приводит нас к следующему графическому пониманию схемы функционирования социально-политической суперэкосистемы (см. рис. 4).

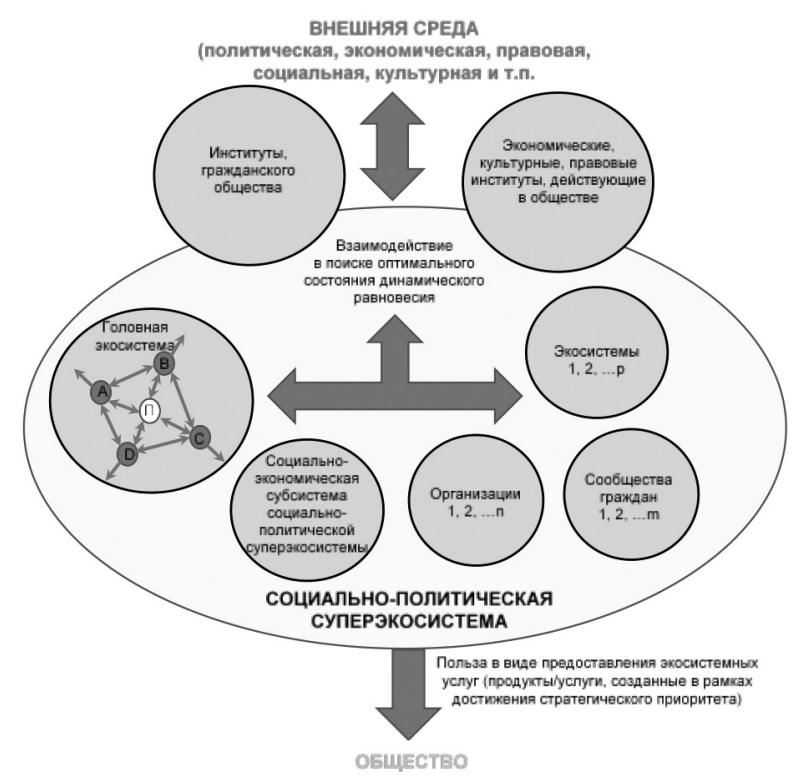

Рисунок 4. Схема функционирования социально-политической суперэкосистемы ( $A, B, C$ и $D$ - компании, принимающие участие в разработке и продвижении проектов в целях достижения государственного стратегического приоритета, П - компания, выполняющая функцию провайдера социально-политической суперэкосистемы).

Создание такой социально-политической суперэкосистемы предполагает переход к самоорганизующейся, саморегулирующейся, саморазвивающейся экосистеме, созданной по модели политической сети, в которой взаимозависимые экосистемы, организации и группы граждан при координирующей роли головной организации - провайдера взаимодействуют между собой для 
обеспечения достижения общественно значимого стратегического приоритета (политический порядок, согласно концепции чикагской школы социологии города). В этом случае функции хаба для экосистемного сетевого взаимодействия и сотрудничества власти, бизнеса и граждан может осуществлять специальная краудсорсинговая платформа, расположенная в организации-провайдере головной экосистемы социально-политической суперэкосистемы и выполняющая функцию коммуникативной площадки.

Используя аналогии с природными экосистемами, можно сформулировать возможные четыре категории социально-политических экосистемных услуг:

- обеспечивающие услуги, например производство частных и общественных благ, необходимых для обеспечения жизнедеятельности членов общества;

- регулирующие услуги, например регулирование производства частных и общественных благ в интересах общества;

- культурные услуги, например производство человеческого капитала, воспитание личности;

- поддерживающие услуги, например разработка нового знания для более эффективного производства частных и общественных благ и повышения качества человеческого капитала.

И в заключение следует отметить следующее. Исходя из гипотезы наличия признаков природоподобия в социально-политических системах, можно попробовать спрогнозировать направление следующей эволюции социальнополитической экосистемы (культурный порядок, согласно концепции чикагской школы социологии города), т.е. неформального и многообразного взаимодействия индивидов в условиях культурной ассимиляции. Подсказку дают известные французские философы Ж. Делез и Ф. Гваттари, рассматривающие общество, в котором отсутствует симметрия, централизация и упорядоченность, по аналогии с корневой системой (ризомой), не имеющей стержневого корня [Делез, Гваттари 2010]. На примере строения ризомы они исследовали концепт «сборки» (agencement), который объясняет возможность соединения крайне разнородных элементов, в том числе и нечеловеческих, в результате чего происходит высвобождение силы «внешнего», создающего в итоге особую сборку. Авторы допускали любые сочетания между техническими, животными и человеческими машинами, т.е. сочетания, результатом которых будут процессы обретения субъектности и индивидуальности, лишь проступающие на горизонте. Благодаря таким сборкам, человек как бы вновь соединяется с природой, стирая различия между действиями «внешнего» и «внутреннего». Такая сборка указывает на место, где возникают ощущения, готовые к встрече с чем-то неразличимым и еще не познанным.

Таким образом, культурная ассимиляция, еще только проступающая на горизонте как концепт-сборка, возможно, будет принадлежать не человеку, а некой виртуальной машине культовости, создающей типы и состояния культуры таким же образом, как на знаменитой картине Э. Мунка «Крик»: по словам Ж. Делеза и Ф. Гваттари, проявляется не лицо, искаженное ужасом, а ужас как внешняя сила (машина), производящая лицо.

\section{Список литературы}

Делез Ж., Гваттари Ф. 2010. Тысяча плато: Капитализм и шизофрения (пер. с франц.; посл. Я.И. Свирского; науч. ред. В.Ю. Кузнецов). Екатеринбург: У-Фактория; М.: Астрель, 2010. 895 с.

Ильичева Л.Е., Кондрашов А.О., Лапин А.В. 2021. Доверие как мост над пропастью неуверенности между властью и обществом. - Мониторинг общественного мнения: экономические и социальные перемены. № 2. С. 162-185. 
Кастельс М. 2000. Информационная эпоха: экономика, общество и культура (пер. с англ. под науч. ред. О.И. Шкаратана). М.: ГУ ВШЭ. 608 с.

Лапин А.В., Цветкова Н.Б. 2021. Изменение образа экосистем в условиях цифровой трансформации общества. - Социально-политические науки. № 6.

Осипов Г.В. 2010. Введение в социологическую науку. М.: Наука; Вече. 332 с.

Перегудов С.П. 2006. Крупная корпорация как субъект публичной политики: учебное пособие для студентов вузов. М.: ИД ГУ ВШЭ; Тольятти: Современник. $162 \mathrm{c}$.

Политические отношения в сетях: система или сообщество: круглый стол. Социально-гуманитарные знания. 2021. № 1. С. 122-163.

Сморгунов Л.В., Шерстобитов А.С. 2014. Политические сети: Теория и методы анализа: учебник для студентов вузов. М.: Аспект Пресс. 320 с.

Стегний А. 2009. Теоретические истоки и особенности институционализации социологии окружающей среды. - Социология: теория, методы, маркетинг. № 3. С. 17-45.

Фадейкина Н.В., Малина С.С. 2021. Развитие теоретических представлений на категории «экосистема» и «инновационная экосистема». -Сибирская финансовая школа. Инвестиции и инновации. № 2(142). 2021. С. 103-111.

Borzel T. 1998. Organizing Babylon - on the Different Conceptions of Policy Networks. - Public Administration. Vol. 76. No. 2. P. 253-273.

Easton D. 1953. The Political System: An Inquiry into the State of Political Science. N.Y.: Alfred A. Knopf. 320 p.

Frosch R.A., Gallopoulos N.E. 1989. Strategies for Manufacturing. - Scientific American. Vol. 261. No. 3. P. 144-153.

Mitleton-Kelly E. 2003. Ten Principles of Complexity and Enabling Infrastructures.

- Complex Systems and Evolutionary Perspectives on Organizations: The Application of Complexity Theory to Organizations. Pergamon. P. 23-50. URL: https://www.researchgate.net/publication/38959109_Ten_principles_of_complexity_and_enabling_infrastructures (accessed 07.01.2022).

Moore J. F. 1993. Predators and Prey: A New Ecology of Competition. - Harvard Business Review. May/June. P. 75-86.

Park R.E. 1955. Society: Collective Behavior, News and Opinion, Sociology and Modern Society. Glencoe, Ill.: Free Press. 358 p.

IL'ICHEVA Lyudmila Efimovna, Dr.Sci. (Pol.Sci.), Professor; Director of Programs of the Center for Public-Private Partnership, Institute of Public Administration and Civil Service, Russian Presidential Academy of National Economy and Public Administration (RANEPA) (84 Vernadskogo Ave, Moscow, 119606, Russia); Chief Researcher at the Institute of Socio-political Research - branch of the Federal Center of Theoretical and Applied Sociology, Russian Academy of Sciences (bld. 2, 13 Borisoglebsky Lane, Moscow, 121069, Russia; lilitcheva@mail.ru)

LAPIN Andrei Viktorovich, Cand.Sci. (Pol.Sci.), Associate Professor of the Chair of Project and Program Management, Faculty of Public Administration of Economics, Institute of Public Administration and Civil Service, Russian Presidential Academy of National Economy and Public Administration (RANEPA) (84 Vernadskogo Ave, Moscow, 119606, Russia; av.lapin@igsu.ru)

\section{ANALYSIS OF ECOSYSTEMS MODELS IN THE VENUE OF SOCIAL DEPOLARIZATION IN SOCIETY}

\footnotetext{
Abstract. Today, a technocratic approach to the term of ecosystem has become entrenched in the consciousness of society,
} which is associated with the image of a set of technological platforms, usually digital, providing products and services to 
the client in a one-stop shop format. However, the natural origin of the concept of ecosystem dictates the use of a different approach based on the interaction within the ecosystem of the subsystem of living and inanimate nature, including humans, and the inorganic environment in the form of a socio-economic subsystem, as a result of which the ecosystem is able to provide society with so-called ecosystem services. Developing the hypothesis of the nature-like essence of social processes in society, the authors put forward the idea that the highest form of ecosystem organization will be a model of a socio-political super ecosystem, or ecosystem of ecosystems, in which the transition to a self-organizing, self-regulating, self-developing ecosystem is realized, created according to the model of a political network. Interdependent ecosystems, organizations and groups of citizens with the coordinating role of the parent provider organization, interact with each other to ensure the achievement of a socially significant strategic priority. In such a super ecosystem, a unified state goal-setting, common moral, ethical and value attitudes of ecosystem actors, along with the possibility of achieving mutual benefit of participants and citizens from socially significant ecosystem activities will allow maintaining a low level of social tension in society, and thereby prevent the emergence of foci of group social polarization.

Keywords: natural ecosystem, social ecosystem, nature-like systems, ecosystem services, social tension, depolarization

НИКОНОВ Владимир Александрович - аспирант Института социологии ФНИСЦ РАН (117218, Россия, г. Москва, ул. Кржижановского, 24/35, корп. 5; nikon561@yandex.ru) ВОРОНОВ Виктор Васильевич - доктор социологическихнаук, профессор; ведущий научный сотрудник Института социологии ФНИСЦ РАН (117218, Россия, г. Москва, ул. Кржижановского, 24/35, кopn. 5; voronov@isras.ru)

\title{
МАЛЫЙ БИЗНЕС МОСКВЫ И ИЗМЕНЕНИЯ ТРУДОВЫХ УСТАНОВОК ЕГО УЧАСТНИКОВ
}

\begin{abstract}
Аннотация. В статье с позиции экономической социологии проведен анализ противоречивости интересов работодателей и наемных работников по отношению к условиям труда в малом бизнесе на примере мегаполиса. Авторы устанавливают ряд неблагоприятных тенденций в сфере трудовых отношений, связанных с низкой заинтересованностью наемных работников в непрестижных видах деятельности, их слабой вовлеченностью в эти отношения при игнорировании их интересов со стороны работодателей. $B$ статье обосновывается необходимость рационального подхода к комплексному процессу формирования кадрового позитивного потенциала малого бизнеса на основе выявленных ценностных ориентиров разных субъектов этого бизнеса мегаполиса.
\end{abstract}

Ключевые слова: мегаполис, малый бизнес, рынок труда, работодатели, наемные работники, условия труда, интересы

Введение. В условиях современного мегаполиса, при растущей атомизации общества, проявляющейся в нарастающей замкнутости, индивидуализме и потребительском отношении граждан друг к другу, приоритетом становятся ориентиры, направленные на удовлетворение личных интересов и потребностей. Со временем трансформация сознания жителей мегаполиса в данном вопросе приобретает все более очевидный характер.

В настоящее время на рынке труда малого бизнеса г. Москвы разрешение проблемы трудовых интересов зачастую переходит в плоскость игнорирования возможных компромиссов в тандеме «работник - работодатель». Не последнюю роль здесь играет избыточная концентрация активной рабочей силы в локальных территориях страны.

Тенденция увеличения численности крупных городов за счет притока человеческих ресурсов с периферии происходит во многих странах мира. 